\title{
Effect of cellulase and Lactobacillus casei on ensiling characteristics, chemical composition, antioxidant activity, and digestibility of mulberry leaf silage
}

\author{
Liwen He, ${ }^{1}$ Wei Zhou, ${ }^{1}$ Cheng Wang, ${ }^{2}$ Fuyu Yang, ${ }^{3}$ Xiaoyang Chen, ${ }^{1 *}$ and Qing Zhang ${ }^{1 *}$ \\ ${ }^{1}$ College of Forestry and Landscape Architecture, Guangdong Province Research Center of Woody Forage Engineering Technology, \\ Guangdong Research and Development Centre of Modern Agriculture (Woody Forage) Industrial Technology, Guangdong Key Laboratory \\ for Innovative Development and Utilization of Forest Plant Germplasm, State Key Laboratory for Conservation and Utilization of Subtropical \\ Agro-bioresources, Integrative Microbiology Research Centre, South China Agricultural University, Guangzhou 510642, China \\ ${ }^{2}$ College of Animal Science, South China Agricultural University, Guangzhou 510642, China \\ ${ }^{3}$ College of Animal Science and Technology, China Agricultural University, Beijing 100193, China
}

\section{ABSTRACT}

With the lack of feed resources in China, mulberry leaves have been developed as a ruminant forage rich in protein and functional components. To make full use of mulberry leaves, including their nutrients and biological activities, we investigated the effects of cellulase and Lactobacillus casei $\mathrm{LC}$ on the nutritive value and antioxidant capacity of mulberry leaf silage. Mulberry leaves from 2 locally prevailing high-yield cultivars were separately subjected to ensiling treatments either with or without addition of Lactobacillus culture, in combination with variable levels of cellulase application. After 60-d ensiling, the resulting silage was sampled and analyzed for fermentation parameters, antioxidant activity, carbohydrates, and protein fractions, as well as in vitro rumen gas production. The results showed that nutrients, including functional components of mulberry leaves, were well preserved during the ensiling process. Compared with the control, the application of cellulase and Lactobacillus casei LC resulted in greater dry matter recovery, higher contents of lactic acid, true protein, and total flavonoid, and increased antioxidant activity and microbial protein production, as well as decreased $\mathrm{pH}$ value, lower concentrations of ammonium nitrogen, and lower fiber fractions in the mulberry leaf silage, which varied between the 2 selected mulberry cultivars. These results suggest that mulberry leaf silage could be a quality feed with robust antioxidant capacity, which could be improved by the application of cellulase and Lactobacillus casei LC.

Received February 12, 2019.

Accepted July 1, 2019.

*Corresponding authors: xychen@scau.edu.cn and zqing_scau@163 .com
Key words: mulberry leaf, antioxidant activity, silage quality, silage additive

\section{INTRODUCTION}

Oxidative stress induced by reactive oxygen species and free radicals can result in cell membrane breakdown or damage, which is usually regarded as one of the causes of several pathologies that affect bovine growth and production, and which can result in significant production loss to farmers (Iqbal et al., 2012; Nisar et al., 2013). Earlier reports indicate that dietary supplementation of exogenous antioxidants could be an effective strategy to combat the effects of oxidative stress (Nisar et al., 2013; Pandey and Negi, 2016). Meanwhile, the search for nutritive antibiotic alternatives and the increasing demand of consumers for natural feed additives have spurred the exploration of natural plant extracts in animal nutrition. Evidence suggests that the use of naturally occurring antioxidants in livestock production could improve animal health, potentially decrease the need for antibiotic supplements, and provide alternative feeding regimens that could still maintain healthy and safe animal products.

Mulberry (Morus spp.), characterized by wide adaptability (Sugiyama et al., 2016) and high protein content (Sánchez-Salcedo et al., 2017; Thaipitakwong et al., 2018), has been considered a promising fodder tree, especially as a protein source. It can adapt to many environmental conditions, from the frigid zone to the tropical zone (Sugiyama et al., 2016). The mulberry field area of China has been estimated to be 700,000 ha, yielding substantial production of 15 to $37 \mathrm{t}$ of mulberry leaves per hectare (Han, 2006). Furthermore, it is documented that the digestible energy and $\mathrm{CP}$ value of mulberry leaves could be as high as those of alfalfa hay (Doran and Laca, 2007), and they could partially 
substitute for expensive supplements in bovine diets with little damage to animal performance (Habib et al., 2016; Alpízar-Naranjo et al., 2017; Tesfay et al., 2018). Meanwhile, the mulberry plant is a conventional herb with multiple pharmacological functions (Thaipitakwong et al., 2018; Yu et al., 2018). The presence of phytochemicals such as phenols (flavonoids, chlorogenic acid) and alkaloids (1-deoxynojirimycin and fagomine) endows mulberry leaves with various biological activities, including antimicrobial, anti-inflammatory, anthelmintic, and antioxidant activities (Zhang et al., 2018). Dietary inclusion of mulberry leaves could benefit animals through the enhancement of total antioxidant capacity and the activities of catalase and superoxide dismutase in serum (Li, 2012; Lin et al., 2017; Si et al., 2018). Thus, mulberry leaves could be a quality feed with important biological activity. However, its preservation presents a problem, because the harvest of mulberry leaves is seasonal, with high accumulation, and natural drying is unrealistic in the rainy season. As an alternative, ensiling, based on lactic acid bacteria (LAB) anaerobically converting water-soluble carbohydrates (WSC) into organic acids (Mcdonald et al., 1991), has proved to be an easy way to preserve wet biomass with low nutrient loss (Ni et al., 2018). Moreover, silage could offer year-round availability of green mulberry leaf forage for ruminants.

Much research proves that mulberry leaves are suitable for silage and that the application of silage additives could improve its quality (Dong et al., 2016; Trabi et al., 2017; Neto et al., 2018). However, to our knowledge, these studies principally focus on the proximate composition but do not refer to the biological activities of mulberry leaf silage. Whether its antioxidant activity could be well conserved during the ensiling process remains unclear. It is hypothesized that additives (LAB and cellulase) would improve the nutrient preservation, including functional components, of mulberry leaf silage. Therefore, the goal of this study was to investigate the effects of Lactobacillus casei LC and cellulase on the ensiling characteristics, chemical composition, and in vitro rumen fermentation, as well as the antioxidant activity, of mulberry leaf silage.

\section{MATERIALS AND METHODS}

\section{Silage Preparation and Sampling}

Silage was prepared according to the procedures outlined by He et al. (2018). Specifically, leaves were collected manually in Guangdong Province, China, from 2 locally prevailing high-yield mulberry cultivars [Yuesang 11 (V1) and Chengxiansang (V2)] at the Zengcheng Experimental Plot of South China Agricultural University. The chopped mulberry leaves (approximately 2 to $3 \mathrm{~cm}$ in length) were separately subjected to ensiling treatments either with or without addition of $L$. casei LC cultures in combination with variable levels of cellulase application in 6 replicates: 1 $\times 10^{6} \mathrm{cfu}$ of $L$. casei $\mathrm{LC} / \mathrm{g}$ of fresh matter $(\mathbf{F M} ; \mathbf{L C})$; $50 \mathrm{U}$ of cellulase/g of FM (E50); $100 \mathrm{U}$ of cellulase/g of FM (E100); $1 \times 10^{6} \mathrm{cfu}$ of LC/g of FM plus $50 \mathrm{U}$ cellulase/g of FM $(\mathbf{L C}+\mathbf{E} 50) ; 1 \times 10^{6} \mathrm{cfu}$ of $\mathrm{LC} / \mathrm{g}$ of FM plus $100 \mathrm{U}$ of cellulase/g of FM (LC+E100); and the blank control (CON). The inoculated LAB ( $L$. casei $\mathrm{LC}$ ) was screened from lucerne silage, as reported previously (Zhang et al., 2016), and the cellulase preparation (Trichoderma reesei) was commercially available, as stated by $\mathrm{He}$ et al. (2018). The given additives were dissolved in $10 \mathrm{~mL}$ of distilled water and sprayed with a mini-sprayer onto $200 \mathrm{~g}$ of fresh leaves, and the control was sprayed with $10 \mathrm{~mL}$ of distilled water. After being evenly mixed, forage was ensiled in laboratory polyethylene bags $(20 \mathrm{~cm} \times 30 \mathrm{~cm})$ and sealed with a food vacuum sealing machine, and the weight of each bag was recorded before storage.

Following 60-d fermentation at room temperature (around $28^{\circ} \mathrm{C}$ ), each bag was weighed to calculate dry matter recovery (DMR) and then sampled in triplicate, with one used to evaluate silage fermentation, the second used for microbial counting, and the third oven-dried $\left(105^{\circ} \mathrm{C}\right.$ for $15 \mathrm{~min}$ and then $55^{\circ} \mathrm{C}$ for $\left.48 \mathrm{~h}\right)$ and ground in a hammer mill to pass through a 1-mm sieve for chemical composition analysis and in vitro fermentation. Additionally, a small proportion of sample (about $10 \mathrm{~g}$ ) of each bag was taken and lyophilized and then ball-milled and stored at $-20^{\circ} \mathrm{C}$ for analysis of antioxidant activity.

\section{Evaluation of Silage Fermentation}

For fermentation parameter measurement, a sample (20 g) of each silage bag was extracted with distilled water $(180 \mathrm{~mL})$; the slurry was kept at $4^{\circ} \mathrm{C}$ overnight and then filtered with qualitative filter paper. The filtrate was used to measure $\mathrm{pH}$, ammonium nitrogen $\left(\mathrm{NH}_{3}-\mathrm{N}\right)$, and lactic, acetic, propionic, and butyric acids. Specifically, the $\mathrm{pH}$ was measured with a glass electrode $\mathrm{pH}$ meter (PHS-3C, INESA Scientific Instrument Co., Ltd., Shanghai, China). The $\mathrm{NH}_{3}-\mathrm{N}$ concentration was determined according to the method of Broderick and Kang (1980), and the organic acids were analyzed via HPLC as previously described (He et al., 2018).

For microbial count evaluation, 20-g samples were extracted with $180 \mathrm{~mL}$ of autoclaved distilled water and then serially diluted. The LAB and coliform bacte- 
ria were incubated (at $30^{\circ} \mathrm{C}$ for $2 \mathrm{~d}$ ) and counted using De Man, Rogosa, and Sharpe (MRS) agar and Violet Red Bile (VRB) agar, respectively. Yeast and molds were separately enumerated on Rose Bengal agar after being incubated at $28^{\circ} \mathrm{C}$ for $3 \mathrm{~d}$.

\section{Analysis of Chemical Composition}

According to AOAC International (2000) procedures, $\mathrm{NDF}, \mathrm{ADF}$, and ADL were analyzed without the use of heat-stable amylase, using an A220 Fiber Analyzer (ANKOM Technology Corp., Macedon, NY), and the results were expressed inclusive of residual ash, where the contents of hemicellulose and cellulose were calculated using the difference between NDF and ADF, and the difference between ADF and ADL, respectively. We analyzed CP using an automatic Kjeldahl apparatus (Kjeltec 8400, Foss Analytics, Hillerød, Denmark). True protein (TP) was determined based on the method of Licitra et al. (1996), and NPN was calculated from the difference between CP and TP. We determined the levels of WSC using 3,5-dinitrosalicylic acid colorimetry (MOA, 2015).

\section{Determination of Total Flavonoid and Antioxidant Activity}

Extract Fluid Preparation. Approximately $0.2 \mathrm{~g}$ of lyophilized sample was weighed into a $15-\mathrm{mL}$ tube and then extracted with $10 \mathrm{~mL}$ of methanol. Following vortex mixing, the tube was kept in dark for $24 \mathrm{~h}$ and shaken every $8 \mathrm{~h}$. Afterward, the extract was collected by centrifugation at $3000 \times g$ for $10 \mathrm{~min}$ and stored at $-20^{\circ} \mathrm{C}$ until further analysis.

Total Flavonoid Determination. Total flavonoid content was determined using the aluminum chloride colorimetric assay according to Singh et al. (2013) with slight modifications. A $0.5-\mathrm{mL}$ extract $(\times 5)$ or standard solution of rutin $(100,200,400,600,800$, and $\left.1,000 \mathrm{mg} / \mathrm{L} ; \mathrm{R}^{2}=0.9988\right)$ was mixed with $0.3 \mathrm{~mL}$ of $5 \%$ (wt/vol) $\mathrm{NaNO}_{2}$ and kept for $5 \mathrm{~min}$, and then 0.3 $\mathrm{mL}$ of $10 \% \mathrm{AlCl}_{3}$ (wt/vol) solution was added and kept at room temperature for another 5 min. Afterward, $2.0 \mathrm{~mL}$ of $1 \mathrm{M} \mathrm{NaOH}$ was added and kept for another 10 min. Finally, the absorbance of the reaction solution was determined at $510 \mathrm{~nm}$ on a Varioskan LUX (Thermo Fisher Scientific, Waltham, MA). Total flavonoid content was expressed as rutin equivalent $(\mathbf{R E}$, milligrams per gram of DM). All samples were analyzed in triplicate.

Radical DPPH Scavenging Activity Assay. The 2,2-diphenyl-1-picrylhydrazyl (DPPH) assay was conducted according to the procedures of Zhuo et al. (2018) with slight modifications. A $0.5-\mathrm{mL}$ extract $(\times 50)$ or standard solution of trolox $(20,30,40,50$, 60 , and $\left.80 \mathrm{mg} / \mathrm{L} ; \mathrm{R}^{2}=0.9993\right)$ was added to $4 \mathrm{~mL}$ of $0.1 \mathrm{~m} M$ DPPH (methanol solution). The mixture was well mixed and then kept in dark for $30 \mathrm{~min}$. The absorbance of the solution was read at $517 \mathrm{~nm}$. The scavenging activity was expressed as trolox equivalent (TE, milligrams per gram of DM). All analyses were performed in triplicate.

Radical ABTS Scavenging Activity Assay. A solution of 2,2-azinobis-3-ethylbenzothiazoline-6-sulfonic acid diammonium salt radical cation (ABTS) was prepared according to Abdennacer et al. (2015). For each assay, ABTS solution was freshly made and diluted 10-fold for determination. A mixture of 0.1-mL extract or standard solution of trolox $(100,200,300$, 400,500 , and $\left.600 \mathrm{mg} / \mathrm{L} ; \mathrm{R}^{2}=0.9981\right)$ and $2 \mathrm{~mL}$ of ABTS diluted solution $(\times 10)$ was kept in dark for 6 min at ambient temperature. The absorbance of the solution was read at $734 \mathrm{~nm}$. The scavenging activity was expressed as trolox equivalent (milligrams of TE per gram of DM). All analyses were performed in triplicate.

Reducing Power (FRAP) Assay. The ferricreducing antioxidant power (FRAP) working solution was prepared according to Abdennacer et al. (2015). The working solution was incubated at $37^{\circ} \mathrm{C}$, and the reactions were completed within $2 \mathrm{~h}$. A mixture of 0.5 $\mathrm{mL}$ of extract $(\times 10)$ or standard solution of trolox $\left(12.5,25,50,60\right.$, and $\left.80 \mathrm{mg} / \mathrm{L} ; \mathrm{R}^{2}=0.9994\right)$ and 4 $\mathrm{mL}$ of the FRAP solution was kept for $30 \mathrm{~min}$ at $37^{\circ} \mathrm{C}$. The absorbance of the solution was read at $593 \mathrm{~nm}$. The reducing power was expressed as trolox equivalent (milligrams of TE per gram of DM). All analyses were performed in triplicate.

\section{In Vitro Rumen Incubation}

Silage samples (approximately $0.5 \mathrm{~g}$ of $\mathrm{DM}$ ) were weighed into $120-\mathrm{mL}$ glass bottles in triplicate in advance. Incubation fluid $(75 \mathrm{~mL})$, made of $25 \mathrm{~mL}$ of rumen fluid and $50 \mathrm{~mL}$ of buffer solution, was added to each bottle. Fresh rumen fluid had previously been collected from 3 rumen-fistulated dairy cows before the morning feeding, and the buffer solution was prepared according to Menke and Steingass (1988). All the bottles were purged with anaerobic $\mathrm{N}_{2}$ for $5 \mathrm{~s}$ and then sealed with butyl rubber stoppers and Hungate's screw caps. Each bottle was individually connected with medical plastic infusion pipes to gas inlets of an automated trace-gas recording system designed by the College of Animal Science and Technology of China 
Agricultural University (Zhang and Yang, 2011), which could continuously record cumulative gas production (GP). All the bottles (with 3 blank controls) were incubated at $39^{\circ} \mathrm{C}$ for $48 \mathrm{~h}$.

The fermentation slurry of each bottle was filtered with pre-weighed nylon bags $(8 \mathrm{~cm}$ by $12 \mathrm{~cm}, 42-\mu \mathrm{m}$ pore size), and the filtrate was used to determine $\mathrm{pH}$ level, $\mathrm{NH}_{3}-\mathrm{N}$ content, and VFA levels, as aforementioned. The residue was oven-dried at $65^{\circ} \mathrm{C}$ for $48 \mathrm{~h}$ to calculate the in vitro dry matter disappearance (IVDMD). In addition, $1 \mathrm{~mL}$ of the filtrate was sampled for microbial crude protein (MCP) measurement (Makkar et al., 1982).

\section{Computation}

Cumulative gas production for each fermentation bottle was fitted to a monophasic model (Groot et al., 1996) as in Equation [1]:

$$
\mathrm{GP}_{\mathrm{t}}=\frac{\mathrm{A}}{\left(1+\left(\frac{\mathrm{C}}{\mathrm{t}}\right)^{\mathrm{B}}\right)}
$$

where $\mathrm{GP}_{\mathrm{t}}$ is the cumulative gas production (milliliters per gram of DM) at incubation time t (hours), $\mathrm{A}$ is the asymptotic GP (milliliters per gram of DM), B is a sharpness parameter determining the shape of the curve, and $\mathrm{C}$ is the time (hours) at which half of $\mathrm{A}$ is reached. The average gas production rate (AGPR, milliliters per hour) was defined as the AGPR at the time when half of A occurred, according to the following equation:

$$
\mathrm{AGPR}=\frac{(\mathrm{A} \times \mathrm{B})}{4 \times \mathrm{C}} .
$$

\section{Statistical Analysis}

Microbial data were normalized by $\log _{10}$-transformation on an FM basis. All data were subjected to 2-way ANOVA with the fixed effects of additives ( $L$. casei LC and cellulase), mulberry cultivar, and additives $\times$ mulberry cultivar, using the GLM procedure of SAS (version 9.0, SAS Institute Inc., Cary, NC). Linear and quadratic responses of cellulase level were assessed using orthogonal polynomial contrast statements. Tukey's test was used for multiple comparisons, with difference declared significant at $P<0.05$. Additionally, Pearson correlation analysis was conducted, to illuminate the relationship between total flavonoid and antioxidant activities using the CORR procedure of SAS.

\section{RESULTS}

\section{Phytochemical, Microorganism and Antioxidant Potential of Raw Mulberry Leaves}

Table 1 shows significant differences $(P<0.01)$ in the contents of DM (31.50\% vs. $35.66 \%)$, TP $(15.96 \%$ vs. $16.99 \%)$, and WSC (13.05\% vs. $11.15 \%)$ between leaves from mulberry cultivars V1 and V2, but no difference $(P>0.05)$ was found in the concentrations of $\mathrm{CP}, \mathrm{NDF}, \mathrm{ADF}$, or ADL. Neither did we find significant differences in the microbial counts of LAB (4.07 and $4.75 \log _{10} \mathrm{cfu} / \mathrm{g}$ of FM), yeast (4.55 and 4.33 $\log _{10} \mathrm{cfu} / \mathrm{g}$ of $\mathrm{FM}$ ), or coliform bacteria (5.39 and 6.03 $\log _{10} \mathrm{cfu} / \mathrm{g}$ of FM). In addition, V1 and V2 mulberry leaves, respectively, contained 68.32 or $66.20 \mathrm{mg}$ of $\mathrm{RE} / \mathrm{g}$ of $\mathrm{DM}$ of total flavonoid and exhibited high radical scavenging activities of DPPH (146.04 and $147.78 \mathrm{mg}$ of $\mathrm{RE} / \mathrm{g}$ of $\mathrm{DM}$ ) and $\mathrm{ABTS}^{+}(21.85$ and $19.62 \mathrm{mg}$ of $\mathrm{RE} / \mathrm{g}$ of $\mathrm{DM})$, along with different $(P<$ 0.05 ) reducing power of FRAP (52.71 vs. $44.71 \mathrm{mg}$ of $\mathrm{TE} / \mathrm{g}$ of $\mathrm{DM})$.

\section{Ensiling Characteristics and Microbial Population of Mulberry Leaf Silage}

No difference $(P>0.05)$ was found in the DMR of mulberry leaf silage from the 2 cultivars. The DMR of CON silage was approximately $90.00 \%$, and the inclusion of additives increased DMR $(P<0.01)$ to a range of 95.68 to $99.64 \%$, except for LC+E100 silage in cultivar V1 (Table 2). Silage of cultivar V1 had a higher $(P<0.01)$ lactic acid concentration and a lower $(P<$ 0.01) $\mathrm{NH}_{3}-\mathrm{N}$ content compared with that of cultivar $\mathrm{V} 2$, and the additives exerted a significant effect $(P$ $<0.01)$ on the $\mathrm{pH}$ value and the contents of $\mathrm{NH}_{3}$ $\mathrm{N}$, lactic acid, and acetic acid in the silage for both cultivars (Table 2). Specifically, compared with CON, all additive-treated silages had lower $\mathrm{pH}$ values, and all silages inoculated with $L$. casei when cellulase was added with it had lower $\mathrm{NH}_{3}-\mathrm{N}$ contents. The additivetreated silages of cultivar $\mathrm{V} 1$ contained more lactic acid and less acetic acid, except for LC+E100-treated silage, whereas only LC and LC+E100-treated silages contained more lactic acid, and LC+E50-treated silage had lower acetic acid concentration in cultivar V2. In LC-inoculated silage, we discovered lower $(P$ $<0.05)$ LAB populations in both cultivars, whereas E100-treated silage in cultivar V2 had a higher $(P<$ 
0.05) LAB population (Table 2). Additionally, propionic acid, butyric acid, and spoilage organisms were undetected in all the silages.

\section{Carbohydrates and Protein Fractions of Mulberry Leaf Silage}

Silage of mulberry cultivar V1 was lower $(P<0.01)$ in contents of DM, NDF, ADF, ADL, cellulose, and WSC and higher $(P<0.05)$ in proportions of TP and hemicellulose compared with that of cultivar V2 (Table $3)$. Additive application affected $(P<0.01)$ the contents of DM, TP, NPN, and structural carbohydrates of mulberry leaf silage for both cultivars (Table 3). Compared with $\mathrm{CON}$, all the additive-treated silages had higher DM contents except for LC+E100-treated silage in cultivar V1, and higher TP concentrations except for E50 and E100-treated silages in V2. Additive-treated silages also showed lower NDF and ADF contents than CON except for E50 and E100-treated silages in V2, and lower hemicellulose content except for LC+E0treated silage in V2. Meanwhile, E50, LC+E50, and $\mathrm{LC}+\mathrm{E} 100$-treated silages in $\mathrm{V} 1$, and $\mathrm{LC}$ and $\mathrm{LC}+\mathrm{E} 100-$ treated silages in V2, had lower NPN concentrations than did CON. All the additive-treated silages in V1, and $\mathrm{LC}+\mathrm{E} 50$ and $\mathrm{LC}+\mathrm{E} 100$-treated silages in V2, had lower cellulose contents, and the additive-treated silages in cultivar V2 were lower than CON in WSC content.

\section{Total Flavonoid and Antioxidant Activity of Mulberry Leaf Silage}

Silage of cultivar V1 was lower $(P<0.01)$ in total flavonoid content and ABTS radical scavenging activity than that of cultivar V2 (Table 4). Compared with CON, most of the additive-treated silages had higher total flavonoid contents and better antioxidant activities (Table 4). In detail, compared with CON, the application of additives increased total flavonoid content except for E100 and LC-treated silages in V1 and E100-treated silage in V2. Additives also resulted in increased ABTS scavenging activity and FRAP reducing power (except for E50-treated) in cultivar V2. Additionally, FRAP reducing power was also increased in the $\mathrm{LC}$ and $\mathrm{LC}+\mathrm{E} 50$-treated silages in cultivar V1, and $\mathrm{DPPH}$ scavenging activity was increased in the LC-treated silage in cultivar V2. Moreover, Pearson correlation analysis showed that antioxidant activities

Table 1. Characterization of raw mulberry leaves from 2 selected cultivars (V1, V2) ${ }^{1}$

\begin{tabular}{|c|c|c|c|c|}
\hline Item & V1 & $\mathrm{V} 2$ & SEM & $P$-value \\
\hline $\mathrm{DM}(\%)$ & $31.50^{\mathrm{B}}$ & $35.66^{\mathrm{A}}$ & 0.33 & $<0.01$ \\
\hline \multicolumn{5}{|l|}{ Protein fractions (\% of DM) } \\
\hline $\mathrm{CP}$ & 19.26 & 19.98 & 0.27 & 0.14 \\
\hline $\mathrm{TP}$ & $15.96^{\mathrm{B}}$ & $16.99^{\mathrm{A}}$ & 0.10 & $<0.01$ \\
\hline $\mathrm{NPN}^{2}$ & 3.31 & 3.10 & 0.44 & 0.74 \\
\hline \multicolumn{5}{|l|}{ Carbohydrates (\% of DM) } \\
\hline NDF & 21.26 & 20.58 & 0.46 & 0.36 \\
\hline $\mathrm{ADF}$ & 10.28 & 10.81 & 0.23 & 0.18 \\
\hline ADL & 2.12 & 2.40 & 0.10 & 0.13 \\
\hline Hemicellulose & 10.99 & 9.77 & 0.51 & 0.17 \\
\hline Cellulose & 8.15 & 8.41 & 0.19 & 0.39 \\
\hline WSC & $13.05^{\mathrm{A}}$ & $11.15^{\mathrm{B}}$ & 0.31 & 0.01 \\
\hline \multicolumn{5}{|l|}{ Microbial counts (log cfu/g of FM) } \\
\hline $\mathrm{LAB}$ & 4.07 & 4.75 & 0.30 & 0.18 \\
\hline Fungi & 4.55 & 4.33 & 0.07 & 0.10 \\
\hline Coliform & 5.39 & 6.03 & 0.20 & 0.09 \\
\hline Molds & $\mathrm{ND}^{3}$ & ND & - & - \\
\hline Total flavonoid (mg of RE/g of DM) & 68.32 & 66.20 & 2.99 & 0.43 \\
\hline \multicolumn{5}{|l|}{ Antioxidant activity (mg of TE/g of DM) } \\
\hline $\mathrm{DPPH}$ & 146.04 & 147.78 & 5.03 & 0.73 \\
\hline ABTS & 21.85 & 19.62 & 2.34 & 0.31 \\
\hline FRAP & $52.71^{\mathrm{A}}$ & $44.71^{\mathrm{B}}$ & 2.52 & 0.02 \\
\hline
\end{tabular}

${ }_{\mathrm{A}, \mathrm{B}}$ Means in the same row followed by different superscript letters differ $(P<0.05)$.

${ }^{1} \mathrm{TP}=$ true protein; $\mathrm{WSC}=$ water-soluble carbohydrates; $\mathrm{FM}=$ fresh matter; $\mathrm{LAB}=$ lactic acid bacteria; $\mathrm{RE}$ $=$ rutin equivalent; $\mathrm{TE}=$ trolox equivalent; $\mathrm{DPPH}=$ free radical DPPH scavenging activity; ABTS = radical $\mathrm{ABTS}^{+}$scavenging activity; FRAP $=$ferric-reducing antioxidant power.

${ }^{2}$ Presented as protein equivalent $(\mathrm{N} \times 6.25)$.

${ }^{3} \mathrm{ND}=$ not detected. 
HE ET AL.

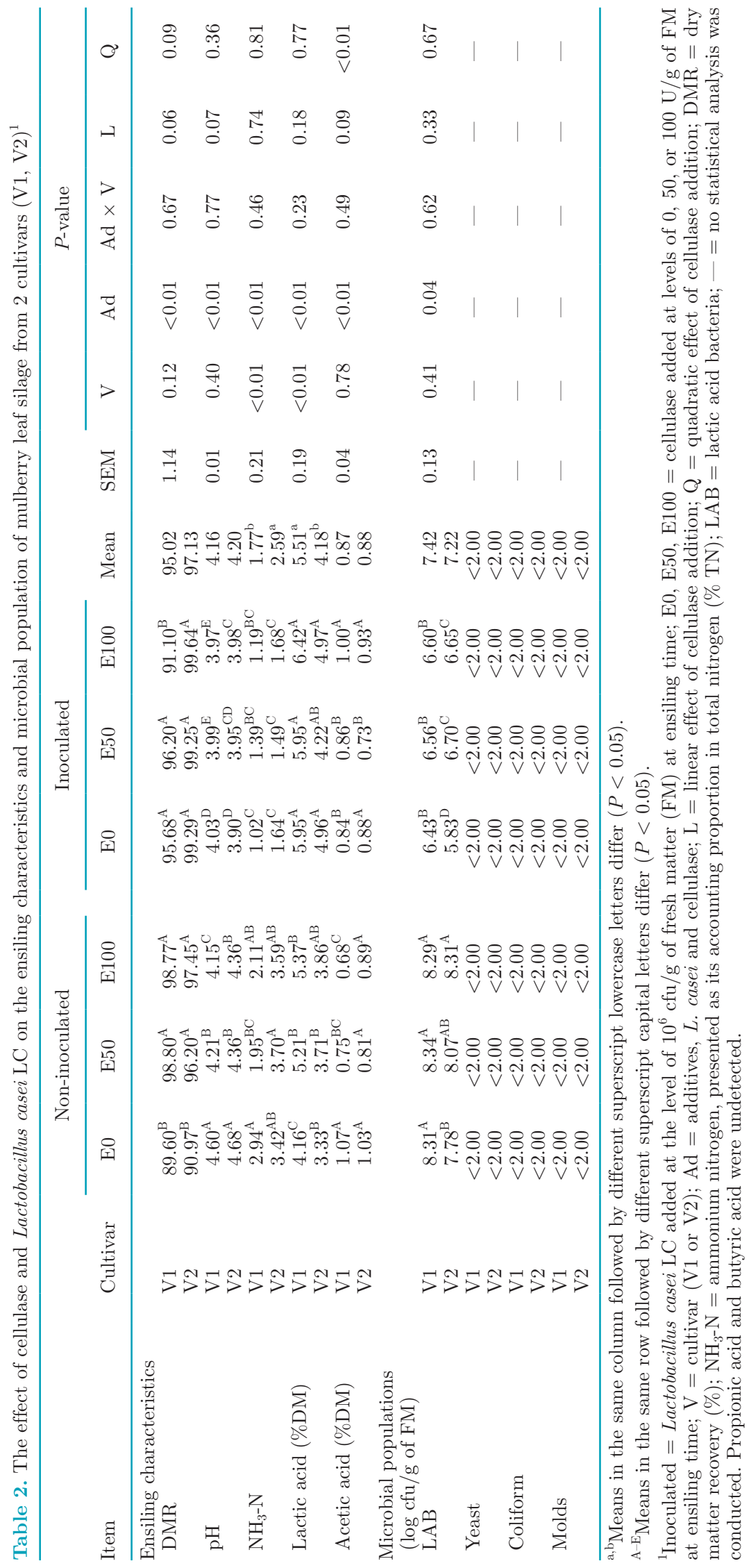


(DPPH, ABTS, and FRAP) were related to total flavonoid content $(P<0.01)$ and were positively correlated $(P<0.05)$ with each other (Table 5$)$.

\section{In Vitro Digestibility and Gas Production Profile of Mulberry Leaf Silage}

The IVDMD of mulberry leaf silage was around $80 \%$ in this study, and it was increased $[P<0.01$; linear effect of cellulase addition (L): $P<0.01$; quadratic effect of cellulase addition $(\mathrm{Q}): P<0.05]$ by additives: the E50 and LC+E100-treated silages in cultivar V1 and E100-treated silage in cultivar V2 had higher IVDMD compared with CON (Table 6). The silage of cultivar V2 had a higher $(P<0.01) \mathrm{B}$ value (the sharpness parameter determining the shape of the curve) of gas production curve than that of cultivar V1, and cellulase exerted an effect (L: $P<0.01 ; \mathrm{Q}: P<0.05$ ) on cumulative gas production at $48 \mathrm{~h}$ (expressed in milliliters per gram of DM) and asymptotic gas production (Table $6)$. With regard to fermentation parameters, silages of cultivar V2 resulted in more MCP yield $(P<0.01)$ and lower $(P<0.05)$ proportions of isobutyric, butyric, isovaleric, and valeric acids than those of cultivar V1. Additive application increased $(P<0.05)$ MCP yield but decreased $(P<0.01)$ total volatile fatty acid content in cultivar $\mathrm{V} 2$ except for $\mathrm{LC}+\mathrm{E} 50$-treated silage. Moreover, additives also affected $(P<0.05)$ the individual molar proportion of acetic, propionic, butyric, and valeric acids, where additive-treated silages led to the decrease of acetic, propionic, butyric, and valeric acid proportions in cultivar V2, except for LC+E50 and LC+E100-treated silages, whereas in cultivar V1, E100-treated silage resulted in lower proportions of acetic and propionic acids, and E50-treated silage resulted in lower proportions of isobutyric and isovaleric acids.

\section{DISCUSSION}

The mulberry leaves used in this study were from the 2 most prevalent cultivars (Yuesang 11 and Chengxiansang) local to Guangdong Province, China, with the advantages of high yield and good resistance to adverse weather conditions. The results presented in this study indicated that mulberry leaves from these cultivars were different in nutrient values. Both our

Table 3. The effect of cellulase and Lactobacillus casei LC on carbohydrate and protein fractions of mulberry leaf silage from 2 cultivars (V1, $\mathrm{V} 2)^{1}$

\begin{tabular}{|c|c|c|c|c|c|c|c|c|c|c|c|c|c|c|}
\hline Item & Cultivar & \multicolumn{3}{|c|}{ Non-inoculated } & \multicolumn{3}{|c|}{ Inoculated } & Mean & SEM & \multicolumn{5}{|c|}{$P$-value } \\
\hline DM (\%) & $\begin{array}{l}\text { V1 } \\
\text { V2 }\end{array}$ & $\begin{array}{l}29.44^{\mathrm{C}} \\
33.80^{\mathrm{C}}\end{array}$ & $\begin{array}{l}32.30^{\mathrm{A}} \\
36.17^{\mathrm{AB}}\end{array}$ & $\begin{array}{l}32.24^{\mathrm{A}} \\
35.67^{\mathrm{B}}\end{array}$ & $\begin{array}{l}31.04^{\mathrm{B}} \\
36.55^{\mathrm{AB}}\end{array}$ & $\begin{array}{l}31.27^{\mathrm{AB}} \\
37.25^{\mathrm{A}}\end{array}$ & $\begin{array}{l}29.53^{\mathrm{C}} \\
37.12^{\mathrm{A}}\end{array}$ & $\begin{array}{l}30.97^{\mathrm{b}} \\
36.09^{\mathrm{a}}\end{array}$ & 0.39 & $<0.01$ & $<0.01$ & 0.24 & 0.41 & 0.36 \\
\hline $\begin{array}{l}\text { Protein fraction } \\
(\% \mathrm{DM})\end{array}$ & & & & & & & & & & & & & & \\
\hline $\mathrm{CP}$ & $\begin{array}{l}\text { V1 } \\
\text { V2 }\end{array}$ & $\begin{array}{l}20.94 \\
21.04^{\mathrm{A}}\end{array}$ & $\begin{array}{l}21.37 \\
21.92^{\mathrm{A}}\end{array}$ & $\begin{array}{l}21.77 \\
21.58^{\mathrm{A}}\end{array}$ & $\begin{array}{l}21.08 \\
20.06^{\mathrm{B}}\end{array}$ & $\begin{array}{l}21.55 \\
21.16^{\mathrm{A}}\end{array}$ & $\begin{array}{l}21.94 \\
21.61^{\mathrm{A}}\end{array}$ & $\begin{array}{l}21.44 \\
21.23\end{array}$ & 0.34 & 0.75 & 0.17 & 0.52 & $<0.01$ & 0.64 \\
\hline NPN & $\begin{array}{l}\text { V1 } \\
\text { V2 }\end{array}$ & $\begin{array}{r}9.14^{\mathrm{A}} \\
10.59^{\mathrm{A}}\end{array}$ & $\begin{array}{l}7.37^{\mathrm{BC}} \\
9.32^{\mathrm{AB}}\end{array}$ & $\begin{array}{l}7.91^{\mathrm{AB}} \\
7.81^{\mathrm{AB}}\end{array}$ & $\begin{array}{l}7.92^{\mathrm{AB}} \\
6.92^{\mathrm{B}}\end{array}$ & $\begin{array}{l}5.98^{\mathrm{C}} \\
7.87^{\mathrm{AB}}\end{array}$ & $\begin{array}{l}7.11^{\mathrm{BC}} \\
7.36^{\mathrm{B}}\end{array}$ & $\begin{array}{l}7.57 \\
8.31\end{array}$ & 0.75 & 0.08 & $<0.01$ & 0.39 & 0.23 & 0.08 \\
\hline $\begin{array}{c}\text { Carbohydrate } \\
\text { components } \\
\text { (\% of DM) }\end{array}$ & & & & & & & & & & & & & & \\
\hline NDF & $\begin{array}{l}\text { V1 } \\
\text { V2 }\end{array}$ & $\begin{array}{l}21.09^{\mathrm{A}} \\
21.87^{\mathrm{A}}\end{array}$ & $\begin{array}{l}17.81^{\mathrm{BC}} \\
19.42^{\mathrm{BC}}\end{array}$ & $\begin{array}{l}16.47^{\mathrm{C}} \\
19.80^{\mathrm{B}}\end{array}$ & $\begin{array}{l}18.64^{\mathrm{B}} \\
20.06^{\mathrm{B}}\end{array}$ & $\begin{array}{l}16.98^{\mathrm{C}} \\
18.32^{\mathrm{BC}}\end{array}$ & $\begin{array}{l}16.73^{\mathrm{C}} \\
17.64^{\mathrm{C}}\end{array}$ & $\begin{array}{l}17.95^{\mathrm{b}} \\
19.52^{\mathrm{a}}\end{array}$ & 0.58 & 0.02 & $<0.01$ & 0.40 & $<0.01$ & 0.20 \\
\hline Hemicellulose & $\begin{array}{l}\text { V1 } \\
\text { V2 }\end{array}$ & $\begin{array}{r}10.76^{\mathrm{A}} \\
9.44^{\mathrm{A}}\end{array}$ & $\begin{array}{l}8.61^{\mathrm{C}} \\
8.12^{\mathrm{B}}\end{array}$ & $\begin{array}{l}7.86^{\mathrm{CD}} \\
8.26^{\mathrm{B}}\end{array}$ & $\begin{array}{l}9.64^{\mathrm{B}} \\
9.41^{\mathrm{A}}\end{array}$ & $\begin{array}{l}8.18^{\mathrm{CD}} \\
8.41^{\mathrm{B}}\end{array}$ & $\begin{array}{l}7.77^{\mathrm{D}} \\
7.95^{\mathrm{B}}\end{array}$ & $\begin{array}{l}8.80^{\mathrm{a}} \\
8.60^{\mathrm{b}}\end{array}$ & 0.27 & 0.03 & $<0.01$ & 0.04 & $<0.01$ & $<0.01$ \\
\hline Cellulose & $\begin{array}{l}\text { V1 } \\
\text { V2 }\end{array}$ & $\begin{array}{l}7.76^{\mathrm{A}} \\
8.58^{\mathrm{A}}\end{array}$ & $\begin{array}{l}6.80^{\mathrm{C}} \\
7.90^{\mathrm{A}}\end{array}$ & $\begin{array}{l}6.50^{\mathrm{C}} \\
8.32^{\mathrm{A}}\end{array}$ & $\begin{array}{l}7.25^{\mathrm{B}} \\
8.15^{\mathrm{A}}\end{array}$ & $\begin{array}{l}6.67^{\mathrm{C}} \\
7.08^{\mathrm{B}}\end{array}$ & $\begin{array}{l}6.60^{\mathrm{C}} \\
6.98^{\mathrm{B}}\end{array}$ & $\begin{array}{l}6.93^{\mathrm{b}} \\
7.83^{\mathrm{a}}\end{array}$ & 0.22 & $<0.01$ & $<0.01$ & 0.89 & $<0.01$ & 0.44 \\
\hline WSC & $\begin{array}{l}\text { V1 } \\
\text { V2 }\end{array}$ & $\begin{array}{l}1.69^{\mathrm{B}} \\
2.75^{\mathrm{A}}\end{array}$ & $\begin{array}{l}2.35^{\mathrm{A}} \\
2.40^{\mathrm{B}}\end{array}$ & $\begin{array}{l}2.01^{\mathrm{B}} \\
2.20^{\mathrm{B}}\end{array}$ & $\begin{array}{l}1.10^{\mathrm{C}} \\
2.12^{\mathrm{B}}\end{array}$ & $\begin{array}{l}1.76^{\mathrm{B}} \\
2.06^{\mathrm{B}}\end{array}$ & $\begin{array}{l}1.83^{\mathrm{B}} \\
2.16^{\mathrm{B}}\end{array}$ & $\begin{array}{l}1.79^{\mathrm{b}} \\
2.28^{\mathrm{a}}\end{array}$ & 0.10 & $<0.01$ & 0.13 & 0.03 & 0.46 & 0.30 \\
\hline
\end{tabular}

${ }_{\mathrm{a}, \mathrm{b}}$ Means in the same column followed by different lowercase superscript letters differ $(P<0.05)$.

${ }^{\mathrm{A}-\mathrm{D}}$ Means in the same row followed by different capital superscript letters differ $(P<0.05)$.

${ }^{1}$ Inoculated $=$ Lactobacillus case $i \mathrm{LC}$ added at the level of $10^{6} \mathrm{cfu} / \mathrm{g}$ of fresh matter $(\mathrm{FM})$ at ensiling time; E0, E50, E100 = cellulase added at the level of 0, 50, or $100 \mathrm{U} / \mathrm{g}$ of FM at ensiling time; V = cultivar (V1, V2); Ad = additives, L. casei and cellulase; L = linear effect of cellulase addition; $\mathrm{Q}=$ quadratic effect of cellulase addition; $\mathrm{TP}=$ true protein; $\mathrm{NPN}=$ presented as protein equivalent $(\mathrm{N} \times 6.25) ; \mathrm{WSC}=$ watersoluble carbohydrates. 


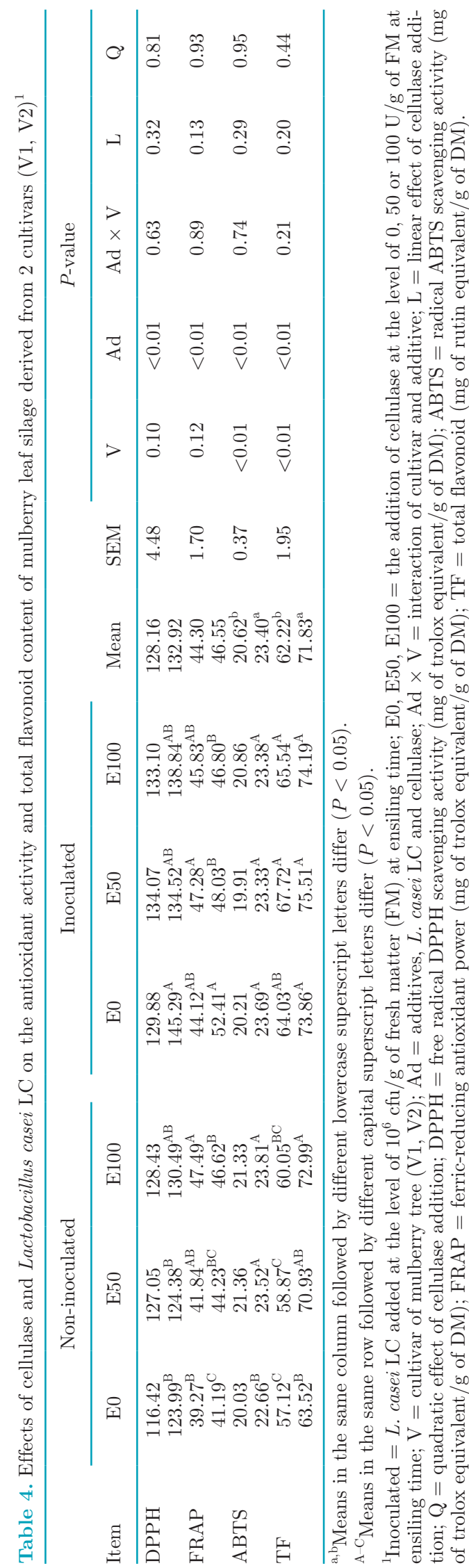

investigations and those of previous studies showed that nutritional and functional components of mulberry leaves were highly dependent on their variety, planting area, and conservation method (Hao et al., 2018; Neto et al., 2018; Yu et al., 2018). Zheng et al. (2017) found wide variation in the contents of DM (61.94 to $79.30 \%)$, CP (13.61 to $24.97 \%$ ), and WSC (3.99 to $17.44 \%$ ) of leaves from 45 mulberry germplasms and varieties. The high WSC content would likely endow mulberry leaves with acceptable silage quality (Mcdonald et al., 1991). It was noteworthy that initial microbial population was another determinant of silage fermentation. The epiphytic LAB load of mulberry leaves was less than 1.0 $\times 10^{5} \mathrm{cfu} / \mathrm{g}$ of fresh weight, even lower than the population of spoilage organisms, which was unfavorable for extensive lactic acid fermentation (Cai et al., 1998). Thus, there may be a need to promote the ability of LAB to establish itself as the dominant microorganism for fermentation, through application of silage additives such as LAB inoculant or cellulase.

Mulberry plants have widely been used in traditional medicines for millennia, where they have been ascribed hypoglycemic, antidepressant, antioxidant, and hepatoprotective properties, which are now believed to correlate to the presence of a large number of bioactive components such as phenols and alkaloids, and especially flavonoids (Kamiloglu et al., 2013; Bao et al., 2016; $\mathrm{Yu}$ et al., 2018). In the present study, mulberry leaves contained more than $66 \mathrm{mg}$ of $\mathrm{RE} / \mathrm{g}$ of total flavonoid and had high antioxidant activity. These results were consistent with those of earlier studies by Liu and Pan (2008), in which the total flavonoid contents of Morus wittiorum and Morus cathayana leaves were observed at 63.92 and $61.17 \mathrm{mg}$ of $\mathrm{RE} / \mathrm{g}$, respectively. It should also be noted, however, that antioxidant activity could be quite different across mulberry species (Iqbal et al., 2012; Zou et al., 2012). A study by Zhang et al. (2018)

Table 5. Pearson correlations between antioxidant activities (DPPH, ABTS, and FRAP) and total flavonoids for mulberry leaf silage ${ }^{1}$

\begin{tabular}{lcccc}
\hline Item & DPPH & FRAP & ABTS & TF \\
\hline DPPH & 1 & & & \\
& & & & \\
FRAP & 0.68 & 1 & & \\
& $<0.01$ & & & \\
ABTS & 0.37 & 0.39 & 1 & 1 \\
TF & 0.03 & 0.02 & 0.68 & 1 \\
& 0.56 & 0.60 & $<0.01$ & \\
\hline
\end{tabular}

${ }^{1} \mathrm{DPPH}=$ free radical $\mathrm{DPPH}$ scavenging activity $(\mathrm{mg}$ of trolox equivalent/g of DM); ABTS = radical ABTS scavenging activity $(\mathrm{mg}$ of trolox equivalent/g of DM); FRAP = ferric-reducing antioxidant power $(\mathrm{mg}$ of trolox equivalent $/ \mathrm{g}$ of $\mathrm{DM}) ; \mathrm{TF}=$ total flavonoid $(\mathrm{mg}$ of rutin equivalent/g of DM). Upper values for each category denote correlation coefficients; lower values denote $P$-value of the correlation. 


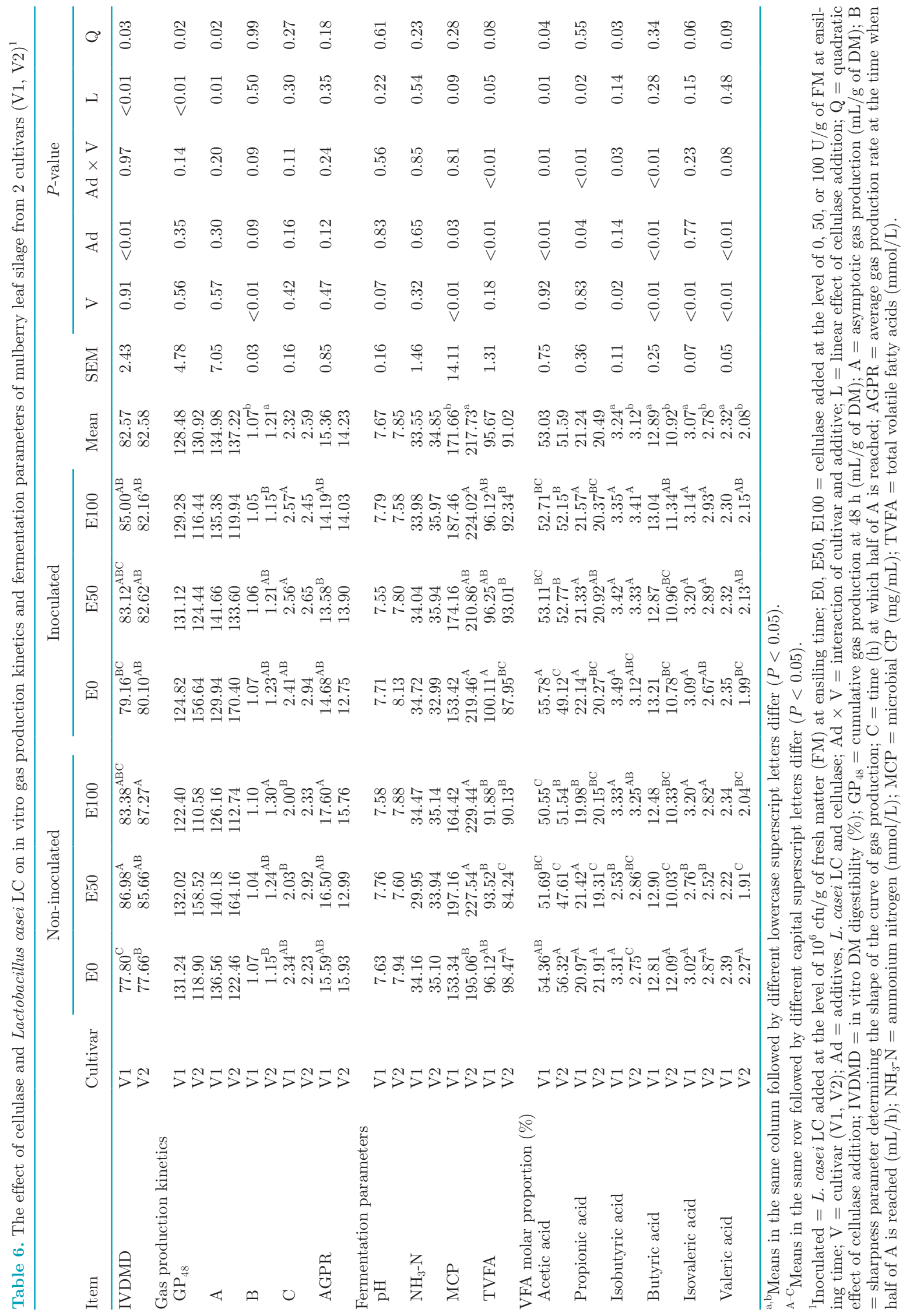


showed that the DPPH scavenging activities of 24 cultivars varied from 25.96 to $70.84 \%$, ABTS free radical scavenging capacity ranged from 0.017 to $0.097 \mathrm{mmol} / \mathrm{g}$, and FRAP values varied from 93.44 to $258.86 \mathrm{mmol}$ of $\mathrm{Fe}^{2+} / \mathrm{g}$. Andallu et al. (2014) reported that mulberry leaf extract significantly scavenged DPPH, nitric oxide, and superoxide radicals in a concentration-dependent manner, inhibited $\mathrm{FeSO}_{4}$-induced lipid peroxidation and hydroperoxides in the erythrocyte membrane model, and also elevated the levels of non-enzymatic antioxidants in the serum of human volunteers. Han (2014) showed that antioxidant application could increase fatty acid content, especially unsaturated fatty acids in high-oil corn silage, in line with the results of Nozière et al. (2006) and Shingfield et al. (2005), likely due to the inhibition of lipoxygenase (Gordon, 2001). Given the reported benefits of antioxidant application, such as anti-lipid oxidation in food conservation (Bozkurt, 2006) and scavenging of free radicals in animal feed (Lin et al., 2017), mulberry leaves could be an important source of natural antioxidants to combat oxidative stress in livestock production.

Ensiling is an easy and effective way to preserve mulberry leaves, and additive application could improve the silage quality (Dong et al., 2016; Trabi et al., 2017). In the present study, additive application improved DMR of mulberry leaf silage, which was in line with Lima et al. (2010) reporting decreased DM losses due to LAB inoculation in the combined silage of sorghum and soybean. This could be because the addition of LAB or cellulase would accelerate LAB fermentation, inhibiting the activity of spoilage organisms and cellular respiration of the harvested plant tissue. Zhao et al. (2018) reported that additives (hemicellulase and Lactobacillus plantarum) caused a rapid $\mathrm{pH}$ decline at the early stage of ensiling and significantly decreased DM loss. As expected, in the present study, additives, especially LC inoculation, increased acid production and lowered silage $\mathrm{pH}$, inhibiting protein hydrolysis. It could be that inoculation with LC increases the initial LAB load, accelerating LAB fermentation, promoting acid production and $\mathrm{pH}$ decline, and inhibiting the activity of spoilage organisms and protein hydrolysis (Heinritz et al., 2012). Our previous study (Zhang et al., 2016) showed that the addition of LC inoculant decreased $\mathrm{pH}$ and $\mathrm{NH}_{3}-\mathrm{N}$ content of Leymus chinensis silage. Additionally, cellulase increased the amount of WSC available to LAB via fiber degradation. Furthermore, it has been reported that LAB inoculants were more effective in ensiling forages with a high WSC concentration (Sun et al., 2009). Addition of LC inoculant and cellulase would exert a synergistic effect on some fermentation parameters in the present study. Additionally, the inoculated silages had a lower LAB population than did non-inoculated silage, which might be related to their lower $\mathrm{pH}$ values.

Protein hydrolysis was inhibited with the application of additives, in view of the low $\mathrm{NH}_{3}-\mathrm{N}$ content and increased TP proportion. Similarly, Moselhy et al. (2015) observed an increase in CP content of silage with addition of LAB and fibrolytic enzymes, which was attributed to proteolysis inhibition and the concentration effect. In addition, functional components might also contribute to protein preservation in mulberry leaf silage, through the inhibition of microbial activity or enzymatic activity. Han (2014) reported that antioxidant application also decreased the $\mathrm{NH}_{3}-\mathrm{N}$ content in high-oil corn silage, attributing this to the inhibition of protease. As for carbohydrates, the contents of NDF, hemicellulose, and cellulose decreased with increasing cellulase addition, which might be the way in which cellulase improves silage fermentation. The results of Dewar et al. (2010) indicated that structural carbohydrates were initially hydrolyzed by enzymes and subsequently by acid hydrolysis during ensiling. Similarly, Ebrahimi et al. (2014) showed that the combination of fibrolytic enzyme and LAB improved the fermentation quality and cell wall degradation of oil palm frond silage.

Not only possessing high nutrient value, mulberry leaves are also rich in functional activity, such as antioxidant activity. However, previous studies have mostly reported the antioxidant capacity of fresh or dry mulberry leaves, with little information on the antioxidant activity of mulberry leaf silage. The present study indicated that antioxidant potential was well preserved during the ensiling process. Polyphenol oxidases (PPO) are generally considered primarily responsible for the degradation of phenolic compounds, which are influenced by temperature and $\mathrm{pH}$ (Huang et al., 2008). However, Tan et al. (2015) reported that the decrease in antioxidant properties for ambient air-dried mulberry leaves was closely associated with the presence of PPO, even though fresh mulberry leaves contained low PPO activity. Likewise, the degradation of anthocyanins was supposed to correlate with the enzymes produced by yeast during wine fermentation, which was inhibited in a few days of fermentation because yeast and PPO competed for the limited oxygen (Romero-Cascales et al., 2005; Wang et al., 2015). Thus, the properties of mulberry leaf silage might be preserved because the anaerobic and low-pH conditions of ensilage inhibited enzyme activity, protecting phenolic compounds from degradation. Furthermore, the additives improved the preservation of total flavonoid and antioxidant activities of mulberry leaf silage by inhibiting the activity of spoilage organisms and promoting $\mathrm{pH}$ decline. Based on these results, we conclude that mulberry leaf silage may 
be used as a functional feed to improve the antioxidant activity of ruminants. Byongtae et al. (2009) analyzed the active components and antioxidant activity of mulberry silage and concluded it has high potential as a functional feed for beef cattle. The results of Cheong et al. (2012) showed that mulberry silage supplementation improved the antioxidant enzyme activities and free radical scavenging activities in the longissimus muscle of beef cattle. Similarly, Si et al. (2018) concluded that dietary inclusion of 10 to $15 \%$ paper mulberry (Morus papyrifera L.) silage might enhance the immune and antioxidant functions of dairy cows and increase PUFA concentrations in milk. Antioxidants also contribute to the nutrient preservation of silage. Han (2014) reported that antioxidant application could increase fatty acid content, especially UFA, and decrease $\mathrm{NH}_{3}-\mathrm{N}$ content in high-oil corn silage.

The functional activities of mulberry leaves are believed to closely correlate to the presence of abundant secondary metabolites, such as flavonoids, alkaloids, and polyphenols (Sánchez-Salcedo et al., 2017; Zhang, et al., 2018). As an important subgroup of plant phenols, flavonoids endow high antioxidant activity, attributable to their polyhydroxy structure (Iqbal et al., 2012; Kamiloglu et al., 2013; Bao et al., 2016). In the present study, Pearson correlation analysis showed that the antioxidant activities (DPPH, ABTS, and FRAP) of mulberry leaf silage consistently correlated with its total flavonoid content. Similarly, the results of Bao et al. (2016) found a significant positive correlation between the antioxidant capacity (DPPH and FRAP assay) and total phenols and flavonoids of mulberry leaves. Moreover, the high correlation among DPPH, ABTS, and FRAP implies that antioxidant capacity measured with different methods remains consistent, suggesting a strong degree of correlation. However, Byongtae et al. (2009) reported that mulberry silage did not contain flavonoids but did contain total phenols of $21.69 \mu \mathrm{g} / \mathrm{mg}$ and presented high free radical scavenging activity. However, different assay methods and species or cultivar variance may explain the discrepancy between these studies. Further studies should help resolve these apparently different results.

In vitro gas production is a simple technique to evaluate feed quality, reflecting the extent and rate of feed fermentation and its digestibility (Getachew et al., 1998). In the present study, additives improved the in vitro DM loss of mulberry leaf silage to some extent, which was consistent with the change of chemical composition, especially fiber fractions. Improved DMR and enhanced fiber hydrolysis resulted in increases of degradable matter in the silage (Zhao et al., 2018). However, improved silage fermentation did not necessarily correlate with increased in vitro gas production.
Rumen gas production mainly derives from fermentation of carbohydrates. A higher extent of fermentation during ensiling would decrease the in vitro fermentation substrate and products. The increased MCP production and decreased total volatile fatty acid content in our study indicated that the energy and nitrogen metabolism were better synchronized and microbial growth was promoted, finally depositing more energy in microbial protein.

\section{CONCLUSIONS}

The present study showed that, compared with CON, mulberry leaf silage treated with cellulase or $L$. casei LC had higher DMR and lactic acid concentration, lower $\mathrm{NH}_{3}-\mathrm{N}$ content and $\mathrm{pH}$ value, improved carbohydrates and protein fractions, higher total flavonoid content and antioxidant activity, and more in vitro MCP yield, which varied between the 2 mulberry cultivars. These results suggest that mulberry leaf silage is a quality feed with high antioxidant capacity, which could be improved by the application of cellulase and $L$. casei LC, especially LC inoculation.

\section{ACKNOWLEDGMENTS}

This work was financially supported by the $\mathrm{Na}$ tional Natural Science Foundation of China Project (31702177, Beijing, China); National Key R\&D Projects (2017YFD0502102-02, Beijing, China); and the Guangzhou Science, Technology and Innovation Commission (201707010462, Guangzhou, China).

\section{REFERENCES}

Abdennacer, B., K. Mattoussi, Y. M'Rabet, N. Rokbeni, M. Dhouioui, and M. Boussaid. 2015. Determination of phytochemicals and antioxidant activity of methanol extracts obtained from the fruit and leaves of Tunisian Lycium intricatum Boiss. Food Chem. 174:577-584.

Alpízar-Naranjo, A., J. Arece-García, M. Esperance, Y. López, M. Molina, and E. González-García. 2017. Partial or total replacement of commercial concentrate with on-farm-grown mulberry forage: Effects on lamb growth and feeding costs. Trop. Anim. Health Prod. 49:537-546.

Andallu, B., M. Shankaran, R. Ullagaddi, and S. Iyer. 2014. In vitro free radical scavenging and in vivo antioxidant potential of mulberry (Morus indica L.) leaves. J. Herb. Med. 4:10-17.

AOAC International. 2000. Official Methods of Analysis. 17th ed. AOAC International, Gaithersburg, MD.

Bao, T., Y. Xu, V. Gowd, J. Zhao, J. Xie, W. Liang, and W. Chen. 2016. Systematic study on phytochemicals and antioxidant activity of some new and common mulberry cultivars in China. J. Funct. Foods 25:537-547.

Bozkurt, H. 2006. Utilization of natural antioxidants: Green tea extract and Thymbra spicata oil in Turkish dry-fermented sausage. Meat Sci. 73:442-450.

Broderick, G. A., and J. H. Kang. 1980. Automated simultaneous determination of ammonia and total amino acids in ruminal fluid and in vitro media. J. Dairy Sci. 63:64-75. 
Byongtae, J., K. Yeongkyu, L. Sangmoo, P. Jaehyun, S. Siheung, P. Pyojam, K. Sungjin, and M. Sangho. 2009. A study on the analysis of functional components and antioxidative activity in mulberry (Morus alba) silage. J. Korean Society of Grassland Forage Sci. 29:743-744.

Cai, Y., Y. Benno, M. Ogawa, S. Ohmomo, S. Kumai, and T. Nakase. 1998. Influence of Lactobacillus spp. from an inoculant and of Weissella and Leuconostoc spp. from forage crops on silage fermentation. Appl. Environ. Microbiol. 64:2982-2987.

Cheong, S. H., K. H. Kim, B. T. Jeon, P. J. Park, I. H. Hwang, N. J. Choi, E. T. Kim, S. K. Hong, J. H. Park, and S. H. Sung. 2012. Effect of mulberry silage supplementation during late fattening stage of Hanwoo (Bos taurus coreanae) steer on antioxidative enzyme activity within the longissimus muscle. Anim. Prod. Sci. 52:240-247.

Dewar, W. A., P. Mcdonald, and R. Whittenbury. 2010. The hydrolysis of grass hemicelluloses during ensilage. J. Sci. Food Agric. 14:411-417.

Dong, Z., X. Yuan, A. Wen, J. Wang, G. Guo, J. Li, X. Bai, S. Zhou, and T. Shao. 2016. Effect of lactic acid bacteria and fermentation substrates on the quality of mulberry (Morus alba) leaf silage. Caoye Xuebao 6:167-174.

Doran, M. P., and E. A. R. D. Laca. 2007. Total tract and rumen digestibility of mulberry foliage (Morus alba), alfalfa hay and oat hay in sheep. Anim. Feed Sci. Technol. 138:239-253.

Ebrahimi, M., M. A. Rajion, G. Yongmeng, A. S. Farjam, A. Q. Sazili, and J. T. Schonewille. 2014. The effects of adding lactic acid bacteria and cellulase in oil palm (Elaeis guineensis Jacq.) frond silages on fermentation quality, chemical composition and in vitro digestibility. Ital. J. Anim. Sci. 13:3358-3368.

Getachew, G., M. Blümmel, H. P. S. Makkar, and K. Becker. 1998. In vitro gas measuring techniques for assessment of nutritional quality of feeds: A review. Anim. Feed Sci. Technol. 72:261-281.

Gordon, M. H. 2001. The development of oxidative rancidity in foods. Pages 7-21 in Antioxidants in Food. J. Pokorny, N. Yanishlieva, and M. H. Gordon, ed. Woodhead Publishing Limited, Cambridge, UK.

Groot, J. C., J. W. Cone, B. A. Williams, F. M. Debersaques, and E. A. Lantinga. 1996. Multiphasic analysis of gas production kinetics for in vitro fermentation of ruminant feeds. Anim. Feed Sci. Technol. 64:77-89.

Habib, G., N. A. Khan, A. Sultan, and M. Ali. 2016. Nutritive value of common tree leaves for livestock in the semi-arid and arid rangelands of Northern Pakistan. Livest. Sci. 184:64-70.

Han, L. 2014. Degradation and inhibition of fatty acids in high-oil corn silages. PhD Diss. College of Animal Science and Technology, China Agricultural University, Beijing, China.

Han, S. 2006. Mulberry resources and its diverse utilization. Guizhou Agric. Sci. 34:118-121.

Hao, J. Y., Y. Wan, X. H. Yao, W. G. Zhao, R. Z. Hu, C. Chen, L. Li, D. Y. Zhang, and G. H. Wu. 2018. Effect of different planting areas on the chemical compositions and hypoglycemic and antioxidant activities of mulberry leaf extracts in Southern China. PLoS One 13:e0198072.

He, L., W. Zhou, Y. Wang, C. Wang, X. Chen, and Q. Zhang. 2018. Effect of applying lactic acid bacteria and cellulase on the fermentation quality, nutritive value, tannins profile and in vitro digestibility of Neolamarckia cadamba leaves silage. J. Anim. Physiol. Anim. Nutr. 102:1429-1436. https://doi.org/10.1111/jpn.12965.

Heinritz, S. N., S. D. Martens, P. Avila, and S. Hoedtke. 2012. The effect of inoculant and sucrose addition on the silage quality of tropical forage legumes with varying ensilability. Anim. Feed Sci. Technol. 174:201-210.

Huang, T., Y. Yang, J. R. Nie, and J. T. Liang. 2008. Study on isolation and activity of polyphenol oxidase (PPO) from mulberry leaves. Food Sci. 12:473-476.

Iqbal, S., U. Younas, K. W. Sirajuddin, R. A. Chan, Sarfraz, and M. K. Uddin. 2012. Proximate composition and antioxidant potential of leaves from three varieties of mulberry (Morus sp.): A comparative study. Int. J. Mol. Sci. 13:6651-6664.
Kamiloglu, S., O. Serali, N. Unal, and E. Capanoglu. 2013. Antioxidant activity and polyphenol composition of black mulberry (Morus nigra L.) products. J. Berry Res. 3:41-51.

Li, W. 2012. Effects of mulberry leaves on performance, serum biochemical parameters, immune function, antioxidation and meat quality in meat sheep. Master's thesis, College of Animal Science, Inner Mongolia Agricultural University, Hohhot, China.

Licitra, G., T. M. Hernandez, and P. J. Van Soest. 1996. Standardization of procedures for nitrogen. Anim. Feed Sci. Technol. 57:347358.

Lima, R., M. Lourenço, R. F. Díaz, A. Castro, and V. Fievez. 2010. Effect of combined ensiling of sorghum and soybean with or without molasses and lactobacilli on silage quality and in vitro rumen fermentation. Anim. Feed Sci. Technol. 155:122-131.

Lin, W. C., M. T. Lee, S. C. Chang, Y. L. Chang, C. H. Shih, B. Yu, and T. T. Lee. 2017. Effects of mulberry leaves on production performance and the potential modulation of antioxidative status in laying hens. Poult. Sci. 96:1191-1203.

Liu, L., and Y. Pan. 2008. Analysis of the total flavonoid content in Folium Mori from different species. Zhongguo Nongxue Tongbao 24:451-488.

Makkar, H. P., O. P. Sharma, R. K. Dawra, and S. S. Negi. 1982. Simple determination of microbial protein in rumen liquor. J. Dairy Sci. 65:2170-2173.

Mcdonald, P., A. R. Henderson, and S. J. E. Heron. 1991. The Biochemistry of Silage. Chalcombe Publications, Kingston, Kent, UK

Menke, K., and H. Steingass. 1988. Estimation of the energetic feed value obtained from chemical analysis and in vitro gas production using rumen fluid. Anim. Res. Dev. 28:7-55.

MOA (Ministry of Agriculture of China). 2015. Determination of soluble sugar in fruits and derived products-3,5-dinitrosalicylic acid colorimetry. In: Agricultural Industry Standard of PRC (NY/T 2742-2015). Ministry of Agriculture, Beijing, China.

Moselhy, M. A., J. P. Borba, and A. E. S. Borba. 2015. Improving the nutritive value, in vitro digestibility and aerobic stability of Hedychium gardnerianum silage through application of additives at ensiling time. Anim. Feed Sci. Technol. 206:8-18.

Neto, A. F. G., J. Da Silva, E. M. Do Nascimento, J. C. S. Lourenço, and S. R. Fernandes. 2018. Nutritional value and physical and chemical characteristics of white mulberry tree using different conservation methods for ruminant feed. Semin. Cienc. Agrar. 39:771-786.

Ni, K., J. Zhao, B. Zhu, R. Su, Y. Pan, J. Ma, G. Zhou, Y. Tao, X. Liu, and J. Zhong. 2018. Assessing the fermentation quality and microbial community of the mixed silage of forage soybean with crop corn or sorghum. Bioresour. Technol. 264:563-567.

Nisar, N. A., M. Sultana, H. A. Waiz, P. A. Para, and S. A. Dar. 2013 Oxidative stress - Threat to animal health and production. Int. J. Livest. Res. 3:76-83.

Nozière, P., B. Graulet, A. Lucas, B. Martin, P. Grolier, and M. Doreau. 2006. Carotenoids for ruminants: From forages to dairy products. Anim. Feed Sci. Technol. 131:418-450.

Pandey, A., and P. S. Negi. 2016. Traditional uses, phytochemistry and pharmacological properties of Neolamarckia cadamba: A review. J. Ethnopharmacol. 181:118-135.

Romero-Cascales, I., J. I. Fernández-Fernández, J. M. López-Roca, and E. Gómez-Plaza. 2005. The maceration process during winemaking extraction of anthocyanins from grape skins into wine. Eur. Food Res. Technol. 221:163-167.

Sánchez-Salcedo, E. M., A. Amoros, F. Hernández, and J. J. Martínez. 2017. Phytochemical properties of white (Morus alba) and black (Morus nigra) mulberry leaves, a new food supplement. J. Food Nutr. Res. 43:253-261.

Shingfield, K. J., C. K. Reynolds, B. Lupoli, V. Toivonen, M. P. Yurawecz, P. Delmonte, J. M. Griinari, A. S. Grandison, and D. E. Beever. 2005. Effect of forage type and proportion of concentrate in the diet on milk fatty acid composition in cows given sunflower oil and fish oil. Anim. Sci. 80:225-238.

Si, B., H. Tao, X. Zhang, J. Guo, K. Cui, Y. Tu, and Q. Y. Diao. 2018. Effect of Broussonetia papyrifera L. (paper mulberry) silage 
on dry matter intake, milk composition, antioxidant capacity and milk fatty acid profile in dairy cows. Asian-Australas. J. Anim. Sci. 31:1259-1266.

Singh, R. S. G., P. S. Negi, and C. Radha. 2013. Phenolic composition, antioxidant and antimicrobial activities of free and bound phenolic extracts of Moringa oleifera seed flour. J. Funct. Foods $5: 1883-1891$

Sugiyama, M., T. Katsube, A. Koyama, and H. Itamura. 2016. Effect of solar radiation on the functional components of mulberry (Morus alba L.) leaves. J. Sci. Food Agric. 96:3915-3921.

Sun, Z. H., S. M. Liu, G. O. Tayo, S. X. Tang, Z. L. Tan, B. Lin, Z X. He, X. F. Hang, Z. S. Zhou, and M. Wang. 2009. Effects of cellulase or lactic acid bacteria on silage fermentation and in vitro gas production of several morphological fractions of maize stover. Anim. Feed Sci. Technol. 152:219-231.

Tan, J. J. Y., Y. Y. Lim, L. F. Siow, and J. B. L. Tan. 2015. Effects of drying on polyphenol oxidase and antioxidant activity of Morus alba leaves. J. Food Process. Preserv. 39:2811-2819.

Tesfay, G., B. Tamir, and G. Berhane. 2018. Substitution of mulberry leaf meal on feed intake, body weight and carcass characteristics of Tigray highland lambs. Indonesian J. Anim. Veter. Sci. 23:28-37.

Thaipitakwong, T., S. Numhom, and P. Aramwit. 2018. Mulberry leaves and their potential effects against cardiometabolic risks: a review of chemical compositions, biological properties and clinical efficacy. Pharm. Biol. 56:109-118.

Trabi, E. B., X. Yuan, J. Li, Z. Dong, A. A. Shah, and T. Shao. 2017. Effect of glucose and lactic acid bacteria on the fermentation quality, chemical compositions and in vitro digestibility of mulberry (Morus alba) leaf silage. Pak. J. Zool. 49:265-273.

Wang, L., X. Sun, F. Li, D. Yu, X. Liu, W. Huang, and J. Zhan. 2015. Dynamic changes in phenolic compounds, colour and antioxidant activity of mulberry wine during alcoholic fermentation. J. Funct. Foods 18:254-265.
Yu, Y., H. Li, B. Zhang, J. Wang, X. Shi, J. Huang, J. Yang, Y. Zhang, and Z. Deng. 2018. Nutritional and functional components of mulberry leaves from different varieties: Evaluation of their potential as food materials. Int. J. Food Prop. 21:1495-1507.

Zhang, D., Y. Wan, J. Hao, R. Hu, C. Chen, X. Yao, W. Zhao, Z. Liu, and L. Li. 2018. Evaluation of the alkaloid, polyphenols, and antioxidant contents of various mulberry cultivars from different planting areas in eastern China. Ind. Crops Prod. 122:298-307.

Zhang, D., and H. Yang. 2011. In vitro ruminal methanogenesis of a hay-rich substrate in response to different combination supplements of nitrocompounds: Pyromellitic diimide and 2-bromoethanesulphonate. Anim. Feed Sci. Technol. 163:20-32.

Zhang, Q., Z. Yu, H. Yang, and R. S. Na. 2016. The effects of stage of growth and additives with or without cellulase on fermentation and in vitro degradation characteristics of Leymus chinensis silage. Grass Forage Sci. 71:595-606.

Zhao, J., Z. Dong, J. Li, L. Chen, Y. Bai, Y. Jia, and T. Shao. 2018. Ensiling as pretreatment of rice straw: The effect of hemicellulase and Lactobacillus plantarum on hemicellulose degradation and cellulose conversion. Bioresour. Technol. 266:158-165.

Zheng, S., W. Zeng, L. Han, C. Liu, M. Yu, Z. Xiang, and A. Zhao. 2017. Comprehensive evaluation of nutritional quality of leaves from 45 mulberry germplasms and varieties. Food Sci. 38:159-163.

Zhuo, Q., Y. Zeng, and Z. Zhu. 2018. Extraction optimization through response surface methodology and antioxidant activity of polyphenols of nymphaea hybrid. Xiandai Shipin Keji 34:206-213.

Zou, Y., S. Liao, W. Shen, L. Fan, C. Tang, C. Y. O. Chen, and Y. Sun. 2012. Phenolics and antioxidant activity of mulberry leaves depend on cultivar and harvest month in Southern China. Int. J. Mol. Sci. 13:16544-16553. 